\title{
PENGEMBANGAN MEDIA E-LEARNING MENGGUNAKAN MOODLE UNTUK MENINGKATKAN HASIL BELAJAR DAN MEMPERKUAT MODEL PEMBELAJARAN DI UNIVERSITAS MUHAMMADIYAH RIAU
}

\author{
Risnal Diansyah, Pitria Ardila \\ Fakultas Ilmu Komputer Universitas Muhammadiyah Riau
}

\begin{abstract}
Abstrak -Perkembangan teknologi informasi berdampak pada semua aspek kehidupan, salah satu bidang yang sangat dipengaruhi oleh perkembangan teknologi informasi adalah bidang pendidikan. Riset terbaru menyebutkan bahwa mahasiswa sekarang menuntut lebih banyak waktu yang berkualitas untuk berdiskusi dan membantu pemahaman dalam perkuliahan. E-learning adalah proses belajar yang menggunakan media elektronik yang bahan-bahan belajarnya dapat diakses setiap saat dan berulang dan dapat meningkatkan pengetahuan terhadap materi pembelajaran tersebut. Sistem pembelajaran yang ada di Universitas Muhammadiyah Riau yaitu adanya pertemuaan antara mahasiswa dan dosen di dalam kelas dalam melakukan proses belajar mengajar. Diskusi terhadap suatu materi pelajaran juga sering dilakukan di dalam kelas, akan tetapi diskusi di dalam kelas ini juga memiliki hambatan seperi keterbatasan waktu

Pada saat ini dosen dalam memberikan materi pelajarannya sudah menggunakan presentasi dan juga sudah menggunakan aplikasi Google Classroom yang menjadi sarana distribusi tugas, submit tugas
\end{abstract}

bahkan menilai tugas-tugas yang dikumpulkan, akan tetapi aplikasi ini tidak dapat diakses melalui satu sistem untuk semua fakultas. Metode yang digunakan dalam penelitian ini adalah wawancara, observasi, dan studi pustaka dan perancangan sistem menggunakan UML. Perangkat lunak e-learning pada Universitas Muhammadiyah Riau ini menggunakan MOODLE sebagai software pembelajarannya.

Kata Kunci : E-Learning, MOODLE, $U M L$

\section{Pendahuluan}

Universitas Muhammadiyah Riau merupakan salah satu Universitas yang sedang berkembang baik dari segi kualitas maupun kuantitas, tentunya harus diimbangi dengan peningkatan SDM. Peningkatan kemampuan SDM di bidang Teknologi Informasi dan Komunikasi dapat dijadikan prioritas utama sebagai jawaban atas isu penguatan mutu pendidikan. Universitas Muhammadiyah Riau berdiri pada tanggal 5 Juni 2008 yang berlokasi di Jalan KH.Ahmad Dahlan, 
No.88 Sukajadi-Pekanbaru, dimana pada saat ini Universitas Muhammadiyah Riau sudah memiliki 7 (tujuh) Fakultas dan 16 (enam belas) Program Studi. Sistem pembelajaran yang ada di Universitas Muhammadiyah Riau yaitu adanya pertemuaan antara mahasiswa dan dosen di dalam kelas dalam melakukan proses belajar mengajar. Pada metode pembelajaran ini mahasiswa cenderung enggan bertanya jika terdapat permasalahan dalam memahami materi pelajaran. Diskusi terhadap suatu materi pelajaran juga sering dilakukan di dalam kelas, akan tetapi diskusi di dalam kelas ini juga memiliki hambatan seperi keterbatasan waktu. Pada saat ini dosen dalam memberikan materi pelajarannya sudah menggunakan presentasi dan juga sudah menggunakan aplikasi Google Classroom yang menjadi sarana distribusi tugas, submit tugas bahkan menilai tugas-tugas yang dikumpulkan, akan tetapi aplikasi ini tidak dapat diakses melalui satu sistem untuk semua fakultas, dengan adanya elearning ini tidak hanya sekedar pendistribusian tugas tetapi di elearning ini dapat diakses melalui satu system untuk (tujuh) fakultas yang ada di Universitas Muhammadiyah Riau sehingga dengan dapat diaksesnya melalui satu sistem, mahasiswa tidak hanya sekedar mengetahui sistem informasi e-learning saja tetapi mahasiswa juga dapat mengetahui informasi-informasi dari fakultas lainnya, adanya forum diskusi online mata kuliah sehingga dapat meningkatkan keaktifan mahasiswa untuk saling berinteraksi baik itu antara mahasiswa dengan dosen ataupun antara mahasiswa dengan mahasiswa.

\section{Landasan teori}

Landasan teori merupakan teori yang relevan yang digunakan untuk menjelaskan variabel yang akan diteliti dan sebagai dasar untuk memberi jawaban sementara terhadap rumusan masalah yang diajukan, dan penyusunan instrument penelitian.

\section{a. Pengertian E-Learning}

Menurut Jaya Kumar C.Koran (2000), e-learning merupakan sebagai media sembarang pengajar danpembelajaran yang menggunakan suatu rangkaian elektronik (LAN, WAN, atau internet) untuk menyampaikan isi pembelajaran, interaksi, atau bimbingan antara staf pengajar dengan para mahasiswa.

\section{b. Komponen E-Learning}

Komponen yang membentuk elearning menurut Rusdy pksi (2012) adalah Infrastruktur e-learning yang dapat berupa personal computer (PC), jaringan komputer, internet, dan perlengkapan multimedia. Sistem dan 
aplikasi e-learning yaitu tentang bagaimana manajemen kelas, pembuatan materi, forum diskusi, sistem ujian online dan segala fitur yang berhubungan dengan manajemen proses belajar mengajar. Sistem perangkat lunak tersebut sering disebut dengan Learning Management System (LMS) dan yang terakhir adalah Konten E-Learning bisa dalam bentuk Multimedia Based Content (konten berbentuk multimedia interaktif) atau Text-Based Content (konten berbentuk teks seperti pada buku pelajaran biasa).

\section{c. Fungsi danManfaat E-Learning}

Menurut Siahaan (2000) ada tiga fungsi pembelajaran elektronik terhadap kegiatan pembelajaran di dalam kelas, yaitu sebagai suplemen yang sifatnya pilihan (optional) apabila peserta didik mempunyai kebebasan memilih apakah akan memanfaatkan materi pembelajaran eletronik atau tidak. Sebagai pelengkap (komplement) yang diprogramkan untuk menjadi materi reinforcement (pengayaan) atau remedial bagi perserta didik di dalam mengikuti kegiatan pembelajaran konvensional. Sebagai pengganti (subtitusi) beberapa Perguruan Tinggi di negara-negara maju memberikan beberapa alternatif model kegiatan pembelajaran atau perkuliahan kepada para mahasiswanya.

\section{d. Modular Object Oriented Dynamic Learning Enviroment (MOODLE)}

Istilah MOODLE singkatan dari Modular Object Oriented Dynamic Learning Environment, yang berarti tempat belajar dinamis dengan menggunakan model berorientasi objek atau merupakan paket lingkungan pendidikan berbasis web yang dinamis dan dikembangkan dengan konsep berorientasi objek, dengan menggunakan MOODLE kita dapat membangun sistem dengan konsep elearning (pembelajaran secara elektronik) ataupun Distrance Learning (pembelajaran jarak jauh), dengan konsep ini sistem belajar mengajar tidak terbatas ruang dan waktu. Seorang guru atau dosen atau pengajar dapat memberikan materi kuliah dari mana saja. Begitu juga dengan seorang mahasiswa dapat mengikuti kuliah dari mana saja.

Berikut beberapa aktifitas pembelajaran yang didukung oleh MOODLE adalah sebagai berikut :

1. Assignment. Fasilitas ini digunakan untuk memberikan penugasan kepada peserta pembelajaran secara online. Peserta pembelajaran dapat mengakses materi tugas dan mengumpulkan hasil tugas mereka dengan mengirimkan file hasil pekerjaan mereka.

2. Chat. Fasilitas ini digunakan untuk melakukan proses chatting 
(percakapan online). Antara pengajar dan peserta pembelajaran dapat melakukan dialog teks secara online

3. Forum. Sebuah forum diskusi secara onlinedapat diciptakan dalam membahas suatu materi pembelajaran. Antara pengajar dan peserta pembelajaran dapat membahas topik-topik belajar dalam suatu forum diskusi.

4. Kuis. Dengan fasilitas ini memungkinkan untuk dilakukan ujian ataupun tes secara online.

5. Survey. Fasilitas ini digunakan untuk melakukan jajak pendapat secara online.

\section{Metodologi Penelitian}

Metode penelitian adalah suatu cara untuk memecahkan masalah ataupun cara mengembangkan ilmu pengetahuan dengan menggunakan metode ilmiah. Adapun tahapantahapan pada penelitian ini adalah sebagai berikut :

\begin{tabular}{|c|c|c|c|}
\hline Kegiatan. & Input & Metode & Output \\
\hline \multicolumn{4}{|l|}{ Mulai } \\
\hline $\begin{array}{l}\text { 1. Mengidentif } \\
\text { ikasi } \\
\text { massalah } \\
\text { 2. Menentukan } \\
\text { Objiek } \\
\text { Penelitian }\end{array}$ & $\begin{array}{l}\text { 1. daftar } \\
\text { pertanyaan. } \\
\text { 2.mengamati } \\
\text { secara } \\
\text { langsung }\end{array}$ & $\begin{array}{l}\text { 1. wawdancara } \\
\text { 2. Observasi }\end{array}$ & Dasta \\
\hline $\begin{array}{l}\text { 1. Menentukan } \\
\text { topik }\end{array}$ & $\begin{array}{l}\text { Pengambilan } \\
\text { referensid dari } \\
\text { berbagai }\end{array}$ & $\begin{array}{l}\text { 1. Studi } \\
\text { Literatur }\end{array}$ & $\begin{array}{c}\text { Judul } \\
\text { penelitian }\end{array}$ \\
\hline $\begin{array}{l}\text { 1. Melakukukan } \\
\text { analisis } \\
\text { strategi } \\
\text { SWOT }\end{array}$ & $\begin{array}{l}\text { Membuat } \\
\text { analisa } \\
\text { SWOT } \\
\text { tethadap } \\
\text { pengembang }\end{array}$ & $\begin{array}{l}\text { 1. Analisa } \\
\text { SWOT }\end{array}$ & Iabeal SWOT \\
\hline & an e-learning & & \\
\hline
\end{tabular}
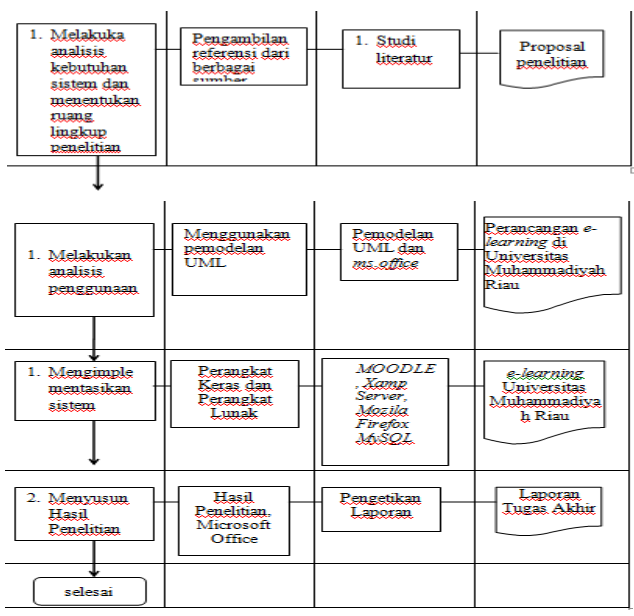

Gambar 3.1 Tahapan Penelitian

\section{a. Tahap Perencanaan}

Pada tahapan perencanaan ini, kegiatan yang dilakukan adalah mengidentifikasi masalah dengan melakukan wawancara untuk mengetahui permasalahan yang terjadi. Setelah itu menentukan objek penelitian dengan cara mengamati secara langsung aktifitas pembelajaran yang terjadi. Dalam hal ini Universitas Muhammadiyah Riau sebagai objek penelitian.

\section{b. Tahap Analisa Kebutuhan Sistem}

Analisa ini memegang peranan penting dalam hal merincikan atau merencanakan sistem baru. Adapun kebutuhan sistem tersebut yaitu kebutuhan perangkat keras dan kebutuhan perangkat lunak.

\section{c. Tahap Analisa Penggunaan}


Analisa penggunaan ini dibuat untuk mengetahui bagaimana rancangan sistem baru dan juga untuk mengetahui proses kerjanya. Analisis penggunaan sistem baru ini menggunakan pemodelan UML

\section{d. Tahap Implementasi}

Tahap implementasi merupakan tahap meletakkan supaya sistem siap untuk dioperasikan.

\section{Hasil dan Pembahasan}

Pada bab ini akan memaparkan tentang analisa sistem yang sedang berjalan, kebutuhan pengguna, analisa sistem baru, pemodelan sistem elearning, dan yang terakhir mengimplementasikan sistem elearning.

\section{a. Analisis Sistem yang Sedang Berjalan}

Pada saat ini dosen dalam memberikan materi pelajarannya sudah menggunakan presentasi dan juga sudah menggunakan aplikasi Google Classroom yang menjadi sarana distribusi tugas, submit tugas bahkan menilai tugas-tugas yang dikumpulkan, akan tetapi aplikasi ini tidak dapat diakses melalui satu sistem untuk semua fakultas. Pada aplikasi Google Classroom kita harus mengikuti kelas, sehingga ketika tidak mengikuti kelas tersebut kita tidak mengetahui informasi di mata pelajaran. Diskusi terhadap suatu materi pelajaran juga sering dilakukan di dalam kelas, akan tetapi diskusi di dalam kelas ini juga memiliki hambatan seperti keterbatasan waktu.

\section{b. Kebutuhan Pengguna}

ebutuhan pengguna dari sistem e-learning ini adalah sebagai berikut :

1. Pengguna dari e-learning ini terdiri dari 5 (lima) orang pengguna yaitu Administrator, Fakultas, Prodi, Dosen, dan Mahasiswa

2. Jika pengguna ingin mengakses elearning ini diharuskan login terlebih dahulu dengan menginput username dan password agar privasi dari masing-masing pengguna terjaga.

3. Pengguna dapat membuat forum diskusi untuk membahas topiktopik tertentu

4. Pengguna dapat membuat forum diskusi dari mata kuliah sehinnga dapat meningkatkan pemahaman terhadap materi pembelajaran tersebut

5. Pengguna dapat melakukan interaksi dengan pengguna lainnya

6. Dapat dilakukannya ujian secara online dengan dengan mengatur lamanya pengerjaan soal

7. Dapatdilakukannya pengumpulan tugas

8. Dapat dilakukannya upload dan download materi

\section{c. Analisa Sistem Baru}


Penggunaan sistem yang baru, diharapkan dapat membantu dalam memperkuat pemberian materi kepada mahasiswa. Analisa sistem baru pada Univeristas Muhammadiyah Riau ini dibuat untuk mengetahui bagaimana rancangan sistem yang baru dan juga untuk mengetahui proses kerjanya. Penerapan sistem e-learning di Universitas Muhammadiyah Riau dimulai dengan dilakukannya analisis. Berikut adalah analisa SWOT terhadap implementasi e-learning di Universitas Muhammadiyah Riau.

\section{d. Diagram Use Case}

Spesifikasi kebutuhan dasar aktor, dalam sistem ini terdiri atas admin, dosen, fakultas, prodi, dan mahasiswa.

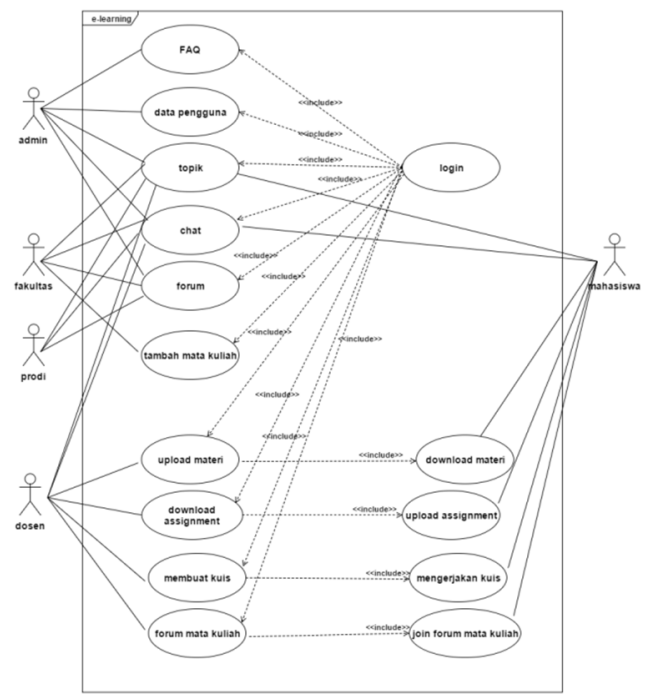

Gambar 4.3 Use Case Diagram

Gambar diatas mejelaskan bahwa pengguna dari sistem e-learning harus melakukan login terlebih dahulu. Untuk dapat mengakses sistem pengguna harus input username dan password. Admin dapat melakukan tambah data pengguna, melakukan chat, tambah topik, input FAQ. Fakultas dapat melakukan chat, tambah topik, dan menambah mata kuliah. Prodi dapat melakukan melakukan chat, tambah topik. Antara admin, fakultas, dan prodi dapat membuat forum diskusi berdasarkan hak akses mereka masing-masing.

Dosen dapat melakukan chat, tambah topik, upload materi, download assignment, membuat kuis, dan membuat forum dari mata kuliah. Mahasiswa dapat melakukan download materi, upload assignment, mengerjakan kuis, dan join ke forum diskusi berdasarkan mata kuliah yang diikuti.

\section{e. Implementasi Sistem}

Implementasi e-learning di Universitas Muhammadiyah ini dilakukan menggunakan MOODLE dengan menggunakan basis data MySQL. Aplikasi ini dapat dijalankan pada

\section{Implementasi Halaman Awal}

Halaman awal merupakan halaman yang akan muncul pada saat menampilkan program atau aplikasi. Pada halaman awal ini pengguna dapat melakukan login ke sisem dengan melakukan input username dan password agar dapat mengakses menu- 
menu yang telah disediakan. Menumenu yang terdapat pada halaman awal ini yaitu e-learning, beranda, link mata kuliah, support, calender, site news, main menu. Penambahan user hanya dapat dilakukan oleh admin untuk dengan tujuan agar dapat dikontrol oleh administrator.

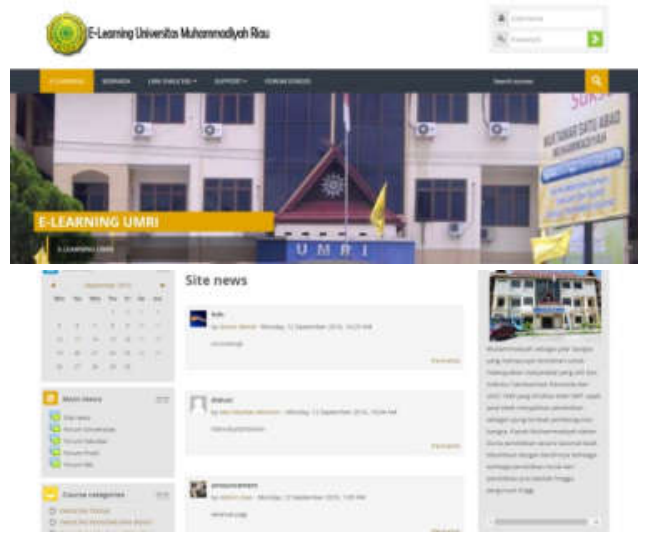

Gambar 4.2 Implementasi Halaman

Utama

\section{Implementasi Halaman Admin}

Halaman ini merupakan tampilan yang muncul pada saat masuk sebagai admin. Pada halaman ini admin dapat melakukan tambah topik, membuat forum diskusi, input FAQ, menambah data penggguna, melakukan chat setelah dilakukannya login. Admin dapat bergabung kedalam forum diskusi Universitas, forum diskusi fakultas, forum diskusi prodi, forum diskusi dosen.

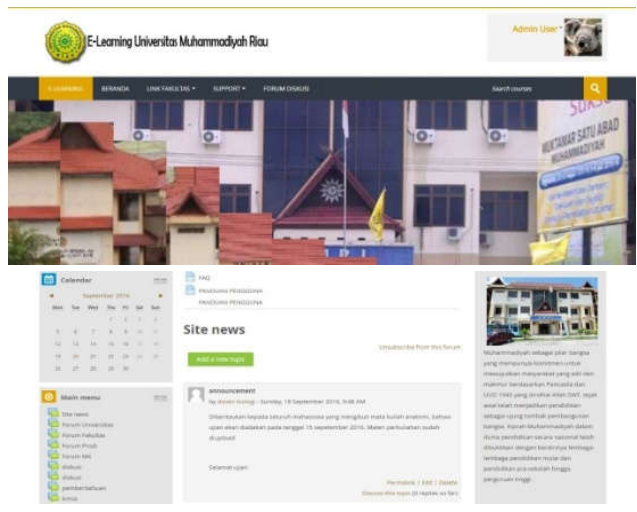

Gambar 4.3Implementasi Halaman Admin

\section{Implementasi Halaman}

\section{Mahasiswa}

Halaman ini merupakan tampilan yang muncul pada saat masuk sebagai mahasiswa. Pada halaman ini mahasiswa dapat melakukan tambah topik, join forum diskusi mata kuliah yang diikuit, melakukan chat setelah dilakukannya login. Mahasiswa tidak dapat bergabung ke fakultas lainnya, kecuali melihat informasi yang dibuat oleh pengguna lainnya.

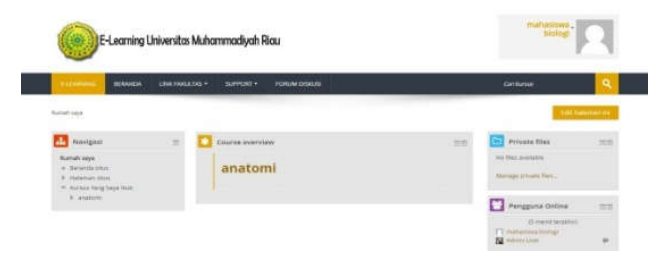

Gambar 4.4 Implementasi Halaman

Mahasiswa

\section{Kesimpulan dan Saran}

\begin{tabular}{lr}
\multicolumn{2}{c}{ Menjelaskan tentang } \\
kesimpulan yang & merupakan \\
rangkuman dari hasil dan pembahasan
\end{tabular}


serta saran untuk penerapan dan pengembangan selanjutnya.

\section{a. Kesimpulan}

Kesimpulan dari keseluruhan
pengembangan e-learning di
Universitas Muhammadiyah Riau
adalah:

1. Mahasiswa dapat mengakses bahan-bahan belajarnya setiap saat dan berulang dan dapat meningkatkan pengetahuan terhadap materi pembelajaran tersebut.

2. Guru atau dosen lebih mudah melakukan pembaruan materi maupun model pengajaran sesuai dengan tuntutan perkembangan keilmuan yang terjadi

3. Website e-learning dapat diakses oleh seluruh fakultas melalui satu sistem

\section{b. Saran}

1. Agar fasilitas e-learning agar dapat ditingkatkan dan dikembangkan serta memberikan jaminan yang layak dan berkualitas

2. Dilakukannya perbandingan terhadap peningkatan belajar mahasiswa menggunakan elearning

\section{DAFTAR PUSTAKA}

Arisa,Ririn,dkk.,2013.Analisa

Pemanfaatan E-Learning Sebagai

Media Pembelajaran Di

Universitas Multimedia

Nusantara.Program Studi Teknik

Informatika.Fakultas Ilmu

Komputer. Universitas Bina

Darma

Gefrie,Ega.,2014.Perbedaan ELearning dan Online Learning. Jurusan Teknik Elektro. Fakultas Teknik .Universiras Negeri Malang

Hasbullah. Perancangan Dan Implementasi Model Pembelajaran E - Learning Untuk Meningkatkan Kualitas Pembelajaran Di JPTK UPI.Jurusan Pendidikan Elektro.FPTK UP

Indrajit,Richardus Eko., 2007. Peranan Strategis Teknologi Informasi bagi Perguruan Tinggi.ABFI Institute Perbanas Jakarta.Faculty of Information Technology

Irsan,Maryo,dkk.,2013.Analisa

Pemanfaatan E-Learning Sebagai Media Pembelajaran Di Universitas Negeri Semarang (UNNES).Program Studi Teknik Informatika.Fakultas Ilmu Komputer.Universitas Negeri Semarang 
J,Y, Wu,dkk.2015.A Moodle-Based ELearning Framework to Conduct the Manipulation Skill Training for an Enterprise Resources Planning. Dept. of Business Administration. Lunghwa University of Science and Technology, Taoyuan, Taiwan

Kumar,Sheo.,Gankotiya,AnilKumar., Dutta,Kamlesh.Dr.,(Mrs).,2011.

A Comparative Study of MOODLE with other e-Learning Systems. Dept. of Computer Science and Engineering. Raj Kumar Goel Institute of Technology for WomenGhaziabad, India

Munawar,Akhmad.,2009.Pengembang an E-Learning Berbasis MOODLE Sebagai Penunjang Perkuliahan Di Jurusan Teknik Elektro Universitas Negeri Semarang.Jurusan Teknik Elektro. Fakultas Teknik.Universitas Negeri Semarang

Nisa,Lulu Choirun.2012.Pengaruh Pembelajaran E-Learning Terhadap Hasil Belajar Mata Kuliah Statistics Mahasiswa Tadris Bahasa Inggris Fakultas Tarbiyah IAIN Walisongo. Fakultas Tarbiyah IAIN Walisongo Semarang.
Prasojo,LantipDiat.,2010.Model

Pembelajaran Berbasis ELearning Manajemen Pendidikan Fakultas Ilmu Pendidikan Universitas Negeri Yogyakarta.Fakultas Ilmu Pendidikan. Universitas Negeri Yogyakarta.

Rodrigues,PatriciaAlves,dkk.,2010. Interactivite Assignment : a MOODLE Component to Enrich the Learning Process.University of Sao Paulo.

Widharta,Willy Prataman., dan Sugiharto,Sugiono.,2013.Penyus unan Strategi Dan Sistem Penjualan Dalam Rangka Meningkatkan Penjualan Toko Damai.Jurusan Manjemen Pemasaran. Universitas Kristen Petra

Indrayani,Etin.,2007.E-Learning:

Konsep dan Strategi

Pembelajaran Di Era Digital (Implementasi Pada Pendidikan Tinggi).

From(http://indrayani.staff.ipdn.a c.id/?p=56).Diakses tanggal 17 April 2016

Yasin,Sanjaya.,2001.Pengertian Sistem Menurut Para Ahli Definisi dan Karakteristik Elemen. From (http://www.sarjanaku.com/2012 /11/pengertian-sistem-menurut- 
para-ahli.html).Diakses

tanggal15 April 2016

Yasin,Sanjaya.,2012.Pengertian

Informasi Menurut Para Ahli

Definisi. From (http://www.

sarjanaku.com/2012/11/pengertia

n-informasi-menurut-para-ahli.

html). Diakses tanggal 15 April

2016 